\title{
Affordances are Signs
}

\section{John Pickering}

Psychology Department

Warwick University, Coventry, UK

e-mail: j.a.pickering@warwick.ac.uk

Abstract: Peirce and Whitehead share a common project: to restrict the over-extension of reductionism, to show how matter must be sensate and to create an ontology of process and subjectivity. This article claims that biosemiotics can assist this project. Moreover, it shows that the concept of affordance is a means to produce a theory of causation that embraces physical, natural and cultural levels of order.

Keywords: Affordance, Gibson, Whitehead, Peirce, Bohm, Biosemiotics

\section{Introduction}

The Cartesian certainty that we exist phenomenologically as well as physically is irreconcilable with Western scientific ontology. How can there be feeling and thought if all there 'really' is is atoms in the void, matter in motion?

Descartes' answer was to add something immaterial to matter. Peirce's answer was different:

"Thought is not necessarily connected with a brain. It appears in the work of bees, of crystals, and throughout the purely physical world ... But ... there cannot be thought without signs" (Peirce 1906: 495).

Peirce supposed that mental life is a universal organic order and is not confined to human experience. Although Peirce had surprisingly little to say about evolution, he surely would have seen it as energised and guided by semiotic interaction. This, in the local conditions of this planet, has seen the progressive, cumulative emergence of physical, biological and cultural systems of order. If this were so, he would have been very like A.N. Whitehead, who proposed that we should see the universe at all levels as an organic process (Whitehead 1938).

Semiotic interaction is an exchange of structured information. It is essential to the emergence, survival and evolution of the structures that endure at all these levels. The physicist David Bohm has suggested that even the minutest parts of physical systems interact via a form of semiosis (Bohm 1985). Von Uexküll viewed the interaction between animals and their surroundings as the detection of and response to signs (von Uexküll 1982b). Baudrillard and Wheeler among many others, show how natural signs of 
the physical and biological levels have been progressively enhanced by those of human culture (Wheeler 2006, Baudrillard 1983).

Adding to this progression of semiotic interpretations, it will be proposed below that affordance, a central concept in James Gibson's ecological approach to perception (Gibson 1986), may also be treated semiotically. The idea of affordance was actually first put forward by Koffka, a major figure in Gestalt psychology who, like his contemporary von Uexküll, had a strong preference for organic holism over mechanistic reduction.

Cultural artifacts and the practices that go with them form a semiotic system that produces, among many other things, the reflexive consciousness that may well be unique to human beings. To fully understand the immense power and productive complexity of this system we need a correspondingly powerful theory that can be applied uniformly to physical, biological and cultural phenomena. This article is a brief proposal that such a theory can be created from the work of Peirce, Whitehead, Gibson and Hoffmeyer.

\section{The Specter of meaning}

We might begin by paraphrasing the opening lines of a work by those two well known semioticians, Marx and Engels: "A Spectre is haunting science - the spectre of Meaning. All the powers of old style reductionism have been exerted for centuries to exorcise this Spectre but have failed. The time is right for those who believe that Meaning is a primordial feature of nature to openly publish their views."

The time is indeed right because developments in the psychological and biological sciences allow the investigation of meaning, semiotics, to accelerate. Moreover, this investigation renders science reflexive, since the search for meaning is, after all, the purpose of science itself as well as the purpose of human life, insofar as it has any. These developments, especially the application of dynamic systems theory, show that the paradigm shift in science from reduction to emergence, which has been taking shape for over a century, is now virtually complete (Laughlin 2005).

Among the many important implications of this shift is the long overdue change in our approach to consciousness, the core of the human phenomenon. The unique reflexivity that distinguishes human from non-human intentionality need no longer be treated as if it were an alien intruder into a world that is 'really' devoid of meaning. Instead, it is something that science not only permits but now also requires, as the developments in particle physics show. As Hunt puts it:

"What is leading when we approach consciousness by means of the non-linear dynamics of interconnectivity and strange attractors? Has the dynamic, open flow of consciousness been explained in quantitative, physical terms? Or has there perhaps been an intriguing sea-change in much of contemporary science, such that, after several hundred years of specific concentration on the linear and the inanimate, we are now beginning to seek out those physical properties of nature that actually mirror the form of our own existence?" (Hunt 1995: 59).

Semiotics in general and biosemiotics in particular has a distinctive and crucial contribution to make in consolidating this change.

\section{An opportunity missed}

In a remarkable example of synchronicity, the sixth Biosemiotic gathering in Salzburg occurred at exactly the same time and place as the sixth annual conference of the International Process Network. The latter oganisation promotes process philosophy in general and the work of $\mathrm{A}$. N. Whitehead in particular. 
Among the objectives of the organisation are: "The exchange of research activities, strategies and results ... Knowledge sharing across all disciplines (such interdisciplinary efforts lie at the heart of A. N. Whitehead's philosophy), enhanced cooperation between institutions doing research and applications of process thought, to provide a seedbed for new cooperative efforts and research projects."

The title of the conference was: The Importance of Process - System and Adventure and further details can be found at: www.processnetwork.org/salzburg2006.htm. In the International Process Network, we encounter a large organisation seeking to make connections. Their conference attracted over 500 scholars from almost every continent, especially China, where interest in process thought is strong because Joseph Needham, who wrote the massive and highly respected History of Science and Civilisation in China was a pupil of Whitehead.

While the gathering in Biosemiotics drew contributions from both Europe and North America, it was nothing like the large international movement represented by the International Process Network. Their conference comprised over 40 parallel sessions and the following were among a number of distinguished keynote speakers: Reginald Cahill (Physics/Flinders University, Australia): "Process Physics and Whitehead: The New Science of Space and Time"; Isabelle Stengers (Philosophy/Brussels University, Belgium): "Achieving Coherence"; Ervin Laszlo (Systems Theory/Pisa, Italy): "The Evolutionary Systems Paradigm".

These titles show the breadth, scope and originality of process thought. They also suggest how appropriate it would be for the biosemiotic movement to seek closer connection with the process community. For example, Stengers is co-author, with the Nobel laureate Illya Prigogine, of La Nouvelle Alliance (Prigogine \& Stengers 1984). This influential book, published in English as Order Out of Chaos, offers, as do Peirce and Whitehead, a more inclusive picture of reality as a critical alternative to over-extended reductionism. Thus, there is every reason to forge closer links here since it would be making contact with a large research community with similar aims to our own.

Having given papers to both conferences, the author of this article can state with confidence that neither had any idea that the other even existed. Despite suggesting to each conference that a joint session would be fruitful, this did not happen. This was a pity, since the opportunity may have been unique and the potential for co-operation was very strong.

\section{Peirce and Whitehead: a common project}

The lack of informed connection between biosemiotics and process thought is surprising. Peirce and Whitehead were attempting a similar project, albeit in different ways. This project is to frame a uniform account of causation, from the physical through the biological to the cultural levels.

For Peirce, this project was to be conducted in terms of semiosis. He claimed that the regularities in phenomena which are known as physical laws are the result of 'nature's tendency to take habits'. In this he was making a radical statement of his belief that what we take to be dead matter was in reality, neither inert nor insensate:

"... it would be a mistake to conceive of the psychical and the physical aspects of matter as two aspects absolutely distinct. Viewing a thing from the outside, considering its relation of action and reaction with other things, it appears as matter. Viewing it from the inside, looking at its immediate character as feeling, it appears as consciousness. These two views are combined when we remember that mechanical laws are nothing but acquired habits, like all the regularities of mind, including the tendency to take habits, itself; and that this action of habit is nothing but generalization, and generalization is nothing but spreading of feelings" (Peirce 1892: 21). 
Thus, for Peirce, it is feeling and the meaning-bearing nature of matter that accounts for evolution as the tendency to take habits. Whitehead, too, saw that it was a mistake to treat matter as a dead abstraction from the organic flow of reality. It is this common project that makes allies of Peirce and Whitehead.

For Whitehead, the project was to be expressed in the language of phenomenology. Not, however, in the sense of the lineage of Brentano and Husserl, which deals primarily with human experience, but in a more fundamental, ontological sense. He proposed that the ultimate constituents of nature are subjects, not objects. While he was suspicious of the whole idea of 'ultimate' constituents, he felt that in as much as they can be found, they would prove to be meaningful events, not material particles.

Now, this claim is hard to place within the Newtonian/Galilean mechanics of the scientific worldview that has dominated the past four centuries or so. But this was precisely Whitehead's point: despite it's predictive power and technological success, that framework is ontologically incomplete and, hence, incorrect. Nature is not mechanistic, it is organic, and experience is a primordial part of it. It is important to note here that Whitehead explicitly acknowledges his debt to William James, especially his philosophy of radical empiricism. James was, in turn, happy to acknowledge his debt to Peirce, of whom he was a staunch supporter.

For both Peirce and Whitehead, then, 'meaning', the proper way to conceive of natural causation was as the exchange of structured information or signs, rather than mere mechanical transmission. We might also note here that von Uexküll too realised that the interaction between an organism and its surroundings is based on mutually evolved meanings, Nature is a harmonious sign system.

Now, to describe something as 'meaningful' raises the spectre of Meaning itself. The very word, as used in English at least, carries with it an important bi-directionality which implicitly brackets subjectivity. When we talk of action, we say that people 'mean' to do something when we judge that they intended to do it. This is of primary importance in law, where only an action that is carried out with conscious intention is an action for which an adult can be held legally responsible. In a complementary sense, we again talk of 'meaning' when we talk of what the world offers by way of communication or of opportunities for action. We ask of a word we don't understand: "What does it mean?". We ask someone who has just, say, undertaken to do something important: "Do you really mean that?". We see that a door has a handle on the left and we know this 'means' that it opens in a particular way.

These are not merely superficial linguistic similarities. They show that meaning itself is the currency of subjectivity, both in the sense of a subject who can act and a subject who can experience. But subjectivity is the Spectre that must be exorcised from science at all costs if an objective, mechanistic worldview is to be preserved. It is important to note that modern psychology emerged when a completely mechanistic picture of the universe seemed possible:

"The great abstract law of mechanical causality now rules the entire universe, as it does the mind of man. It is the steady, immutable pole star, whose clear light falls on our path through the labyrinth of the countless separate phenomena" (Attributed to Ernst Haeckel in Barfield, 1926: 188.)

But such a view banishes meaning from the world since the one thing a mechanism patently can not do is to deal with the world in a meaningful way, in the sense of 'meaning' set out above.

\section{The Spectre returns}

Ironically, very little of contemporary psychology is equipped to address meaning in this sense. This is due to the machine metaphor that has shaped the subject for the last fifty years or so. It was at first pro- 
ductive and helpful. It allowed the restrictive behaviourism of the early part of the last century to be superseded by information processing models of cognition. These were part of what is now called "The Cognitive Revolution" (see e.g. Gardner 1985) and were a great advance on what had up to then been unconvincing behaviourist theories. For one potent example, Chomsky's critique of Skinner's Language Behaviour marked a turning point in psychology. After the 1950's, structuralist, that is, meaning-based, theories, such as those of Piaget for development, Chomsky for language and Bruner for thinking, became dominant.

However, the information processing metaphor, especially in mechanistic computer models of the mind, in turn became a limitation. As Jerome Bruner, a major figure in the Cognitive Revolution pointed out:

"The cognitive revolution, with its fixation on mind as information processor, has led psychology away from the deeper objective of understanding mind as the creator of meanings. ... when it concerns itself centrally with meaning, psychology inevitably becomes a cultural psychology and ... must venture beyond the conventional aims of positivist science with its ideals of reductionism, causal explanation and prediction. To reduce meaning or culture to a material base ... is to trivialise both in the service of misplaced concreteness. ... psychology will fare better when it realises that its truths ... are relative to the point of view it takes towards that condition" (Bruner 1990, page xiii).

It is surely no accident that Bruner uses Whitehead's phrase 'misplaced concreteness'. In treating the brain as if it were a computer, psychology lost sight of what should be its central concerns, namely, the nature of consciousness and how the human mind, and other minds for that matter, deal in meaning. Fortunately, as the limitations of strict mechanistic models have become clear, the era of reducing mental life to mere information processing is closing. Cognition is being reclaimed from the mechanistic metaphor (Freeman \& Nunez 1999).

\section{Psychology recovers consciousness}

Psychology is returning to approaching mental life, including conscious experience, as necessarily embodied in the actions of particular organisms and embedded in the contingencies of particular circumstances. This is called the embodied approach to cognition. It is actually the recovery of a position set out in 1890 by William James, in his never-bettered Principles of Psychology.

The embodied approach also resembles Whitehead's organic philosophy of process, especially as he sets it out in Modes of Thought (Whitehead 1938). There he criticises philosophy and psychology for neglecting the body as the vehicle for the mind. Towards the end of Modes of Thought, Whitehead also criticises what he calls the "Fallacy of the perfect dictionary". This is the belief that philosophy and science can, or should, aim to develop a complete conceptual vocabulary with which to explain the nature of the world and the place of human experience in it. He proposes instead that philosophy must remain conceptually open and productive. Only then will it become possible to recognise and investigate those aspects of nature that actually mirror the form of productive human experience.

This productivity was also a primary concern of Peirce. In his view, it arises from continual semiotic chaining, in which the meaning of thoughts and experiences constantly unfold to create the flow of experience. Peirce saw in semiotics the means to create a complete metaphysical system. Thus, the semiotic flow is not confined to human beings, but arises throughout nature. Treating biosemiotics as the application of Peirce's ideas to the causal structure of living systems allows us to re-frame and update our understanding of the continuity of biological and cultural evolution (Kull 2004, Wheeler 2006). 
Now, as cultural systems are the accumulated products of human action within social settings, there may seem to be less need here to concern ourselves with other forms of life as they act within their natural settings. But this is a mistake, as it takes attention from what Abrams reminds us is a 'more than human world' (Abrams 1997). To neglect the actions and experience of other mental beings is to ignore the vast matrix of mutually evolved organic order from which the human social world and human mental life emerged only very recently. We need to create a correspondingly powerful theory to address this emergence.

Combining Whitehead, biosemiotics and embodied cognition will help to do this. Hoffmeyer too, reminds us that while human meanings are naturally the most immediate and salient to human concerns, they are neither the first nor the only meanings in the biosphere: "We did not invent meaning. This world has always meant something. It just did not know it" (Hoffmeyer 1993: 146). It knows it now, thanks to the evolution of the reflexive capacities of the human mind. These, in turn, have brought science to the position where it can engage with the problem of meaning itself.

Embodied cognition is a start on rebalancing the anthropocentrism of the cogito and correcting the mistake of taking the abstract uniformity of computation for the diversity of natural cognition. It strikes a more even balance between human and non-human meanings and has terminated the search for a unified, computational theory of cognition. Minds do not hold representations in order somehow to compute from them how to act. From the perspective of embodied cognition, meaningful action comes first. As Goodwin puts it "Organisms live their lives, they don't compute them" (Goodwin 1999: 231).

\section{A natural history of meaning}

This observation can serve as a motto for embodied cognition. It signals a turn away from the formal abstractions of the computational metaphor. It helps psychology to move forward, around the impasse of mechanistic metaphysics, towards to the more biologically plausible project of creating a natural history of meaning. We are beginning to address the why of mental life as well as the how. The answer is: to permit interaction within a system comprising both organism and environment, guided by natural signs and the feelings that are intrinsic to being alive.

Embodied cognition helps to take psychology on beyond the limitations of both Behaviourism and the computational metaphor. Although these two schools are often presented in histories of psychology as a paradigm shift, the conceptual and methodological continuity between them is clear. Both used mechanistic metaphors for mental life and both, in their rigid adherence to the natural science model, reflected psychology's struggle for status and recognition in the academic world (e.g. Pickering 2000, Valsiner 1991).

Mechanistic approaches to mental life were also of little interest to Brentano, Husserl and their phenomenological lineage. For them, the principal point of interest about mental life is intentionality. That is, consciousness is primordially about something and seldom, if ever, neutral. This aboutness has intrinsically to do with value and meaning.

Now Peirce identified aboutness with signification. This semiotic stance is perhaps hard to place in a scientific worldview that takes nature to be non-living and incapable of action unless acted upon. However, Peirce was wary of making the distinction between living and non-living too strongly. It is a tribute to his foresight that an increasing number of contemporary scientists are likewise wary. Work in artificial life, in genetics, in evolutionary theory, thermodynamics and microphysics are pointing beyond the mechanistic metaphysics of the nineteenth century. 
For those seeking a new metaphysical framework, Peirce's semiotic stance towards nature and Whitehead's organicism are an attractive combination. In Whitehead's view, and contrary to the assumptions of most natural scientists over the past couple of centuries, nature cannot be captured in static particulars or by measuring the state of a system at a particular point in space and time. "There is no reality at an instant" as he put it. He warned against what he called "fallacy of misplaced concreteness" (Whitehead 1929: 66), which is to take the regularities that natural science abstracts from reality for reality itself. Adopting this fallacy is to view nature as, primarily, inert particles of dead matter that are only mechanically and externally related. While technological achievements show this view is reliable and productive that does not guarantee that it is ontologically significant. This mechanistic worldview denatures nature, disenchants the world and renders lived experience something secondary and even alien.

Whitehead, like William James, found this view impoverished and sought to enrich it. In his organic worldview, experience was the primary feature of nature. He advocated treating nature as a process made up of patterns of internally mediated relationships between subjects. Nature's creative advance depends on action taken in the service of feelings and the search for meaning and value. These feelings are not confined to those which like human beings are able to observe and describe. They are present at every level of nature, from organisms to atoms. In this metaphysical framework scientific inquiry into nature takes on an organic character. As he put it: "Biology is the study of large organisms, physics is the study of smaller ones" (Whitehead 1929: 125).

Causality in this view is more like the unjustly neglected Aristotelian notion of a formal cause, rather than the material and efficient causes that are the major, and exclusive, concern of contemporary natural science and technology. Formal causation depends on the flow of information rather energy or the transmission of mechanical force. Matter is not merely acted upon but is bound up in evolving patterns of organic interaction in which structured causes produce correspondingly structured effects. Within these patterns causation is more than merely mechanical. Although physical laws are not broken within these patterns, they are nonetheless secondary. The primary causes at work are, as Peirce proposed, semiotically mediated interactions.

\section{Beyond boundaries}

Peirce sought to create the semiotic foundations of pragmatism. It was this that so attracted James and, after him, Dewey and Rorty. Pragmatism holds that there are no brute facts of nature. The world means nothing until interpreted. Interpretation is however not a human monopoly, as shown by the quotation from Peirce at the start of this article. This is not to say that bees and crystals think in anything like the way that human beings think, and they surely cannot know they are thinking, as Descartes realised human beings can.

It is to say, though, that thought does not come into existence with the human condition. It is graduated and is prefigured in the operations of the pre-human and the pre-organic world. Indeed, in Whitehead's view, there is no pre-organic world. To believe that there was would be to add an unnecessary boundary to our view of reality:

"... there are no clear divisions anywhere ... when you push your observations beyond the presuppositions on which they rest ... Any division, including some activities and excluding others, also severs the patterns of process which extend beyond all boundaries. ... connectedness is the essence of all things of all types" (Whitehead 1938: 21).

Peirce too, proposed that thought and causality are essentially semiotic and present at all levels of the natural order. Accepting this, the boundary between mind and matter dissolves. 
David Bohm's treatment of what he refers to as the 'unbroken wholeness of nature' is likewise boundary free (Bohm and Hiley 1993: 381 - 388). Elsewhere Bohm attempts to broaden the treatment of meaning by suggesting a radical reinterpretation of all causation as essentially formal causation (Bohm 1985). He pictures the totality of phenomena from the sub-atomic scale to human social structures as a continuous hierarchy. Causality in this hierarchy is essentially formal although material causes are a necessary vehicle. Objects can respond to their environments by virtue of their internal relations as opposed to just "billiard-ball" material causality. Parts of the system guide each other rather than merely moving each other. Bohm includes levels of organisation usually included within the field of application of biosemiotics, thus:

"... the physical environment both natural and the cultural is the result of meanings; these fundamentally affect our actions towards nature and the action of nature back on us ... simpler meanings are just reflexes built into the nervous system that reflect the accumulated experience of a species ... with higher animals and man meanings become cultural ... self-conscious ..." (Bohm1985).

Jacob von Uexküll too used semiosis as the means by which to understand the continuity of the preorganic and organic orders of nature, and, like Bohm, he made no qualitative distinction between them. Von Uexküll's notion of the Umwelt is the sphere of meaning around all sentient beings that makes the world comprehensible (Von Uexküll 1982). What things 'mean' to an active organism is a matter of interpretation, not merely a reflex or brute physical causation. What the active organism 'means' to do is guided and energised by signs in its surroundings. In turn, these signs trace a history of mutual transactions between active organisms and their surroundings. Thus bees perceive in the ultra-violet range and flowers have ultra-violet patterns that act as guide paths to where their nectar is. The bee's perceptual system and the flower's pigmentation are the semiotic complements of each other. The transactions of meaning that have accompanied the co-evolution of all levels of the natural order are the semiotic deep structure of reality.

While no clear boundary can be drawn between natural and conventional signs, the interactions of animals, plants and their surroundings are the concern of biosemiotics, the study of natural signs (e.g. Sebeok \& Umiker-Sebeok 1992). Hoffmeyer combines Peirce and Von Uexküll to create a theory of organic order that resembles that of Whitehead:

"Subjectivity has its roots in the cosmos ... We need a theory of organisms as subjects to set alongside the principle of natural selection; Jacob von Uexküll's Umwelt theory is just such a theory" (Hoffmeyer 1993: 57).

Hoffmeyer's semiotic interpretation of nervous activity resembles the phenomenologist's concern with intentionality:

"... intentionality is the idea that our mental states are always "about" something "out there". $\quad . .$. From a biological point of view there is nothing surprising in this ... animals have nervous systems and brains; ... and from the dawn of evolution their purpose has been to control bodily actions, behaviour" (Hoffmeyer 1993: 47).

Human intentionality, a product of the transition from biological to cultural evolution, is atypical in being reflexive, but primordial pre-reflexive intentionality, according to Hoffmeyer has been present from the 'dawn of evolution'. He chides philosophers who find intentionality problematic. They only do so, he points out, because:

"... they never consider that mental "aboutness" - human intentionality - grew out of a bodily "aboutness" (i.e. the behaviour necessary to ensure reproduction and survival) - what could be described as 
evolutionary intentionality, the anticipatory power inherent in living systems. We still cannot escape the fact that our minds remain embodied" (Hoffmeyer 1993: 47).

This is very close to what proponents of embodied cognition claim:

"There is a movement afoot in psychology to grant the body a role in shaping the mind" (Wilson 2002: 625).

Likewise, it matches Whitehead's observations on 'aboutness', like the following, which is one of many:

"Thus if we wish to understand the relation of our personal experience to the activities of nature, the proper procedure is to examine the dependence of our personal experiences on our personal bodies" (Whitehead 1938: 218).

The similarities between Whitehead, biosemiotics and embodied cognition turn on just this: what we are conscious of is shaped both by what we are intending to do in the present and by traces of what we have done in the past left in the nervous system and in the environment. Thus it is not helpful to try to formalise cognition as computation nor to abstract it from the forms of life in which it occurs. It functions as a semiotic system by which organisms interpret the signs in their surroundings that indicate how they may act.

\section{Affordance and Action}

The ecological psychology of James Gibson, especially in its notion of affordance, is concerned with exactly this: how organisms have evolved to respond directly to opportunities for action. Gibson proposed that the energy reaching an organisms sensory systems is richly structured by the objects and events encountered by that organism. Moreover, the sensory systems of that organism will have evolved to be able directly to detect those properties within that structure which Gibson called 'invariants'. Invariants unambiguously specify what is there in the environment and are thus what the organism needs to know in order to act adaptively. Affordances are an important type of invariant which indicate where actions with important outcomes are possible:

"There is information in the light to specify affordances .... this radical hypothesis implies that the value and meaning of things can be directly perceived. The affordances of the environment are what it offers the animal .... either for good or ill. By affordance I mean something that implies the complementarity of the animal and the environment. The notion that invariants are related at one extreme to the motives and needs of an observer and at the other extreme to the substances and surfaces of a world provides a new approach to psychology" (Gibson 1979: 179).

Thus affordance describes the relationships between organisms and their niches in a similar way to Bohm and Von Uexküll, though at a more specific level (Alley 1985). Ecological psychology, by stressing that organisms and their niches are systems of mutually evolved relations, makes the origin of meaning more comprehensible. Organism and niche are integrated by the exchange of meaning. Affordances are behavioural meanings, they are signs to an organism that actions are possible. It is important to note here that affordance cannot only refer to natural objects such as branches that may be grasped or fruit that may be eaten, but also to culturally constructed objects, like handles which may be turned to open a door.

Now semiotics, particularly in Europe, has generally followed Sassure's lead and paid more attention to cultural than to natural signs. However, semiotics in the American context was a far more general enterprise and a means for unifying science: 
"The concept of the sign may prove useful in unification of the psychological, sociological and humanistic sciences ... and since signs are simply the objects studied by the biological and physical sciences related in certain complex functional processes ... this provides for the unification of the psychological ... with the physical and biological sciences" (Morris 1938: 2).

Von Uexküll proposed a similar role for semiotics, which he saw as:

"... a science that embraces natural systems of signs alongside and before the human system ... one that breaks down the division between natural and human sciences. The basis of this science is a reversal of the picture of reality offered by traditional science ... true reality lies behind the "nature" that physicists, chemists and biologists conceive of ... and reveals itself through signs ... the rules and laws to which these signs are subject are the only real laws of nature" (Non Uexküll 1982a: 2).

Affordances, which deal with both natural and conventional signs, are a link of the sort that Morris and von Uexküll proposed. They are the behavioural meanings of the environment for particular organisms. We can thus explore the fit between ecological psychology and biology by using the theoretical vocabulary of semiotics.

What does labeling affordances as signs achieve? Does it, as Peirce and Morris might have hoped, assist with the unification of the sciences? The sciences in this case being ecological psychology, biology and cognition? Paradoxically, it may do so by making clearer a special case where full unification is impossible. That case is the human perceiver.

The characteristic reflexivity of human cognition means that we are not only able to perceive the world as it is, that is, to perceive the affordances that actually surround us, but also to perceive affordances that do not yet exist, that is, to perceive the world as if it were otherwise. When we take a rock and modify it with blows until it functions as a blade, we do just that. We not only perceive what is, but also what may be and hence we may take meaningful, intentional action to bring it about if we so choose.

Once that capacity evolved in our human ancestors, the way was open to accumulate and improve cultural artifacts and practices, something Tomasello and co-workers have termed the 'Ratchet Effect' (Tomasello et al. 1993). This has led, in time, to the emergence of the built environment within which the human mind has evolved and in within which it develops. The affordances of this environment are natural, artificial and every shade in between. To provide a uniform account of how the range is perceived and used requires a semiotic theory of the sort that is being sketched here.

\section{Conclusions: Embracing the Spectre}

Such a unified account is possible, but only by re-admitting the spectre of Meaning into science. But with meaning comes subjectivity, which is impossible to address with the current theoretical resources of science. These resources need to be enriched and biosemiotics is essential if this is to happen.

As Hoffmeyer reminds us:

"The world is full of subjects and something must have created them. But latent within that 'something' there must, inevitably, be 'someone'. Subjectivity has its roots in the cosmos and, at the end of the day, the repression of this aspect of our world is not a viable proposition'"' (Hoffmeyer 1996: 57).

So we end by returning to the question with which this article began: "How can feeling and thought exist if there is only matter in motion?". The answer is, by recognising that feeling and thought are primordially present in matter. 
It is this that energises and guides and evolution as Whitehead and Henri Bergson both recognised (Bergson 1907). In his last works, published posthumously, Merleau-Ponty, Bergson's heir, moved emphatically into an ontological view that rested on Whitehead's organicism (Merleau-Ponty 2003). His notion of 'maximum grip' is a clear statement that what drives evolution and development is the effort after meaning. Human beings, like all organisms are teleonomic, that is they make the effort to find meaning in their surroundings and their experience. What makes us unique is that we are able to observe and modulate that effort. The social and cultural evolution of the past fifty thousand years or so has seen this effort amplified and accelerated. The result is what Baudrillard calls 'Hyper-reality', a cultural milieu in which sign value has replaced use- and exchange-value (Baudrillard 1983).

Matter is sensate, and this primordial intentionality, this mind-stuff, has been concentrated into autopoietic systems which preserve and diversify themselves through mutual semiotic evolution, modifying the environment in the process. The human environment, thus becomes a special case since it is a largely a human creation from which the unique reflexivity of human experience emerges. To understand this emergence we will need a theory of the sort that has been sketched here.

\section{References:}

Abram, D. (1997) The Spell Of The Sensuous: Perception And Language In A More-Than-Human World. New York. Vintage Books. Alley, T. (1985) Organism-environment mutuality, epistemics and the concept of a niche. In: Synthese, 65. pp $411-444$.

Barfield, O. (1926) History of English Words. London. Faber \& Faber.

Baudrillard, J. (1983) Simulations. Translated by Paul Foss, Paul Patton and Philip Beitchman. New York. Semiotext[e].

Bergson, H. (1907) Creative Evolution. Paris. Gallimade

Bohm, D. \& Hiley, B. (1993) The Undivided Universe. London. Routledge.

Bohm, D. (1985) Unfolding Meaning. London. Fontana.

Bruner, J. (1990) Acts of Meaning. London. Harvard University Press.

Freeman, W. \& Nunez, R. (1999) Reclaiming Cognition: The Primacy of Action, Intention and Emotion. In: Journal of Consciousness Studies, $6(11-12)$. pp ix - xix.

Gardner, H. (1985) The Mind's New Science: A History Of The Cognitive Revolution. New York. Basic Books.

Gibson, J. (1979) The Ecological Approach to Visual Perception. New Jersey. Erlbaum.

Goodwin, B. (1999) Reclaiming a life of quality. In: Journal of Consciousness Studies, 6 (11 - 12). pp 229 -236.

Haeckel, E. (1899) Die Weltraetsel was originally published in Germany, probably in Jena. In: The Riddle of the Universe at the Close of the Nineteenth Century. Published in 1992 by Prometheus Books, NY.

Hoffmeyer, J. (1993) Signs of Meaning in the Universe. Bloomington. Indian University Press.

Hunt, H. (1995) On the Nature of Consciousness. London. Yale University Press.

Kull, K. (2004) Uexküll and the postmodern evolutionism. In: Sign System Studies, 32 (1 -2). pp 99 - 114.

Laughlin, R. (2005) A different Universe (Reinventing Physics from the Bottom Down). New York. Basic Books.

Merleau-Ponty, M. (2003) Nature: Course Notes from the College de France, D. Seglard, ed. R Vallier, trans. Evanston. Northwestern University Press.

Morris, C. (1938) The foundations of the theory of signs. In: International Encyclopedia of Unified Science. Vol. 1, No. 2: Foundations of the Unity of Science. Chicago. University of Chicago Press.

Peirce, C.S. (1892) Man's Glassy Essence. In: The Monist, (3). pp 1 - 22

Peirce, C. S. (1906) Prolegomena to an Apology for Pragmaticism. In: The Monist, (16). pp 492 - 497

Pickering, J. (2000) Methods are a Message. In: Velmans, M. (Ed.) (2000) Investigating Phenomenal Consciousness: Methodologies And Maps. Amsterdam. John Benjamins. Pages $279-300$.

Sebeok, T. \& Umiker-Sebeok, J. (Eds.) (1992) Biosemiotics: The Semiotic Web. Berlin. Mouton de Gruyter.

Tomasello, M., Kruger, A. \& Ratner, H. (1993) Cultural learning. In: Behavioral and Brain Sciences, 16. pp 450-88.

Von Uxeküll, T. (1982a) Jacob von Uexküll's Theory of Meaning. In: Semiotica, 42. pp 1 - 24.

Von Uxeküll, J. (1982b) The Theory of Meaning. In: Semiotica, 42. pp 25 - 82.

Valsiner, J. (1991) Construction of the Mental. In: Theory and Psychology, 1(4). pp 477 - 494.

Wheeler, W. (2006) The Whole Creature: complexity, biosemiotics and the evolution of culture. London. Lawrence \& Wish art.

Whitehead, A. (1929) Science and the Modern World. Cambridge University Press.

Whitehead, A. N. (1938) Modes of Thought. Cambridge University Press.

Wilson, M. (2002) Six views of embodied cognition. In: Psychonomic Bulletin \& Review, 9(4). pp 625 - 636. 